\title{
Changes in exercise haemodynamics during treatment in pulmonary arterial hypertension
}

\author{
S. Provencher*, , P. Hervé ${ }^{\circ}$, O. Sitbon* ${ }^{*}$ M. Humbert*, G. Simonneau* and D. Chemla
}

ABSTRACT: Improvement in exercise capacity may not be associated with significant changes in resting pulmonary haemodynamics. The present prospective study documented the relationships between improvement in 6-min walking distance (6MWD) and changes in resting and exercise pulmonary haemodynamics after treatment in patients with idiopathic pulmonary arterial hypertension (IPAH).

A total of 42 IPAH patients underwent supine submaximal exercise haemodynamic assessments at baseline and after $5 \pm 2$ months of therapy. The 6MWD, the corresponding chronotropic response (peak minus resting heart rate), and resting and exercise haemodynamic variables were analysed. The isoflow was defined as the lowest of the pre- and post-treatment peak cardiac index (Cl). The extrapolated isoflow mean pulmonary artery pressure $\left(\bar{P}_{\mathrm{pa}}\right)$ was used to characterise changes in $\bar{P}$ pa-Cl regression lines following treatment.

Patients were given bosentan $(n=28)$, epoprostenol $(n=12)$ or both. The 6MWD increased significantly, from $399 \pm 88$ to $442 \pm 86 \mathrm{~m}$. On univariate analysis, changes in $6 \mathrm{MWD}$ correlated with changes in isoflow $\bar{P}$ pa, chronotropic response, resting haemodynamics $(\mathrm{Cl}$, pulmonary vascular resistance and mixed venous oxygen saturation) and exercise haemodynamics (peak $\mathrm{Cl}$ ). On multivariate analysis, only changes in isoflow $\bar{P}_{\text {pa }}$ and chronotropic response were independently associated with changes in 6MWD.

Improvement in exercise tolerance with chronic therapy is independently related to improvement in pulmonary haemodynamics measured in exercise but not in resting conditions.

KEYWORDS: Exercise haemodynamics, pulmonary hypertension

$\mathbf{R}$ ecently introduced treatments for idiopathic pulmonary arterial hypertension (IPAH) target three distinct pathobiological pathways, mediated by prostacyclin, endothelin and nitric oxide, respectively. When added to conventional therapy (diuretics and anticoagulants), these treatments significantly improve the functional status and outcome of patients suffering from this extremely severe disease [1]. Most clinical trials have shown beneficial effects of these treatments on exercise capacity, as reflected in the functional class and 6-min walking distance (6MWD) [2]. The 6MWD is now part of routine IPAH evaluation, as it provides benchmarks for disease severity, response to therapy and progression [2]. However, there has been disappointment related to the fact that correlations of standard haemodynamic measurements with functional outcome are loose in IPAH. The potential reasons why pulmonary haemodynamic measurements do not tightly correlate with clinical state in patients with IPAH are two-fold. First, in most reported studies, haemodynamic measurements are performed at rest, when right ventricle stress and related symptoms are minimal. Secondly, a single-point measurement of mean pulmonary artery pressure $\left(\bar{P}_{\text {pa }}\right)$, pulmonary artery occlusion pressure $(P$ pao $)$ and cardiac output (CO), and derived pulmonary vascular resistance (PVR) calculation, may be misleading because the inherent assumptions of linearity and zero crossing of the driving pressure-CO relationship are not met [3]. Indeed, multipoint $\left(\bar{P}_{\text {pa- }} P\right.$ pao $) / C O$ coordinates are described by a linear approximation, but present with a positive extrapolated pressure intercept in IPAH [3]. Thus, single-point PVR determinations at variable flow may underestimate or overestimate changes in the pulmonary circulation $[4,5]$. These errors can be avoided by defining incremental PVR as the slope of the multipoint pressure-flow line [3]. Recent studies have shown that improvement in exercise capacity with prostacyclin therapy may not be associated with significant changes in pulmonary haemodynamics

\section{AFFILIATIONS}

${ }^{*}$ Centre des Maladies Vasculaires Pulmonaires (UPRES EA 2705), Service de Pneumologie et Reanimation Respiratoire, AP-HPUniversité Paris Sud XI, Hôpital Antoine Béclère, Clamart,

- Centre Chirurgical MarieLannelongue, Le Plessis-Robinson, ${ }^{+}$Service de Physiologie, EA4046, CHU de Bicêtre, Le Kremlin-Bicêtre France.

\#Centre de Recherche de I'Hôpital Laval, Institut Universitaire de Cardiologie et de Pneumologie, Université Laval, Quebec City, QC Canada.

CORRESPONDENCE

S. Provencher

Hôpital Antoine Beclere

157 rue de la Porte de Trivaux 92140 Clamart

France

Fax: 33146303824

E-mail: steve.provencher@ crhl.ulaval.ca

\section{Received:}

January 182008

Accepted after revision:

March 222008

\section{SUPPORT STATEMENT}

$S$. Provencher has received a fellowship grant from the Chaire J.D. Bégin (Université Laval, Quebec City, QC, Canada)

\section{STATEMENT OF INTEREST}

Statements of interest for S. Provencher, 0. Sitbon, M. Humbert and G. Simonneau can be found at www.erj.ersjournals.com/ misc/statements.shtml

European Respiratory Journal Print ISSN 0903-1936 Online ISSN 1399-3003 
at rest, whereas incremental PVR defined by a multipoint pressure-flow plot shows improvement with therapy [3]. As a result, recent guidelines suggest that pulmonary haemodynamics should be measured both at rest and during exercise to evaluate responses to therapy by defining a pulmonary pressure-flow relationship in patients with IPAH $[6,7]$.

According to these recommendations, the current authors investigated pressure-flow relationships in IPAH patients both before and after chronic treatment with bosentan, epoprostenol or both. More specifically, the hypothesis tested was that exercise haemodynamics were more accurate than resting haemodynamics for the prediction of changes in 6MWD in patients with IPAH receiving chronic treatment.

\section{METHODS}

\section{Study population and protocol}

From January 2004 to December 2004, consecutive patients referred to the Hôpital Antoine Béclère (Clamart, France) for the evaluation of newly diagnosed IPAH were prospectively included in the study. The diagnosis of IPAH was based on recent guidelines [8]. A total of 42 patients (24 females and 18 males, mean \pm SD age $48 \pm 13$ yrs) were included, all naïve to prostacyclin derivatives, endothelin receptor antagonist, phosphodiesterase type- 5 inhibitor, calcium channel blocker, digoxin and $\beta$-blockers. Functional status was evaluated using the World Health Organization (WHO) functional classes [9]. A 6min walking test was performed, as recommended by the American Thoracic Society [10]. Resting and peak heart rates were measured, and the chronotropic response was calculated (difference between peak and resting heart rates), as described previously [11]. Patients underwent haemodynamic evaluation as part of their routine workup. The study was approved by the current authors' institutional review board (Hôpital Antoine Béclère) and informed consent was obtained from each patient.

\section{Haemodynamic evaluation}

The resting haemodynamic evaluation was carried out according to the current authors' routine protocol. The haemodynamic evaluation was carried out in the supine position. The electrocardiogram and arterial oxygen saturation measured by pulse omixetry were monitored continuously. Mean systemic arterial pressure was measured at the brachial artery (Dynamap 1800; Critikon, Tampa, FL, USA). Right heart catheterisation was performed using the Seldinger technique with an $8 \mathrm{~F}$ sheath inserted via the jugular or basilic vein. The right heart catheter was a 7F, two-lumen, thermodilution pressure-measuring tipped catheter (Corodyn TD; Braun Medical, Bethlehem, PA, USA). CO was measured using the thermodilution technique, and three values differing by $<10 \%$ were averaged. Stroke volume index and cardiac index (CI) were calculated using standard formulas. Resting haemodynamics were characterised by determining $\bar{P}_{\text {pa }}, \mathrm{CI}$, and PVRi (computed as $\left.\left(\bar{P}_{\text {pa }}-\bar{P}_{\text {pao }}\right) / \mathrm{CI}\right)$ at rest. Right ventricular stroke work was calculated as $\left(\bar{P}_{\mathrm{pa}}\right.$ minus right atrial pressure $) \times 0.0136 \times($ stroke volume $)$ Stroke index (stroke work/body surface area) was also calculated.

Exercise tests were performed in supine position on an electronically braked cycle ergometer (Cycline 100; Tecmachine, Andrezieux-Boutheon, France) secured to the catheterisation table. Haemodynamic values were first measured at rest. Following this, pressure and flow were measured with the patient's legs positioned on the pedals. The patient was then instructed to pedal at a rate of $60 \mathrm{rpm}$, the workload being increased stepwise by $10 \mathrm{~W}$ every $3 \mathrm{~min}$ from $0 \mathrm{~W}$ to a maximum workload of $40 \mathrm{~W}$, depending on the patient's functional tolerance. Haemodynamic parameters were measured during the last minute of each exercise level. All measures were obtained at steady state (that is, unchanging $\bar{P}_{\text {pa }}$ and heart rate). The mean (range) number of data points per patient was 6 (5-7) both at baseline and at follow-up evaluation. The $\bar{P}_{\text {pa }}$ and $\mathrm{CI}$ at rest and at each workload were plotted for each patient, and incremental total pulmonary resistance was calculated as the slope of the $\bar{P}_{\mathrm{pa}}-\mathrm{CI}$ relationship. Ppao was not obtained at each exercise level for all patients, either for technical reasons (i.e. not possible to obtain reliable $P$ pao) or because the operator considered that the manoeuvre involved undue risk to the patient. Consequently, the $\bar{P}$ pa-CI relationship was studied instead of the $\left(\bar{P}_{\text {pa- }}-P_{\text {pao }}\right) / C$ I relationship.

\section{Characterisation of haemodynamic changes with therapy and repeatability of haemodynamic measurements}

Patients were given bosentan $(n=28)$, intravenous epoprostenol $(n=12)$, or both $(n=2)$. Functional status, the 6 -min walk test and exercise haemodynamics were evaluated after 46 months of treatment (mean $5 \pm 2$ months).

Calculated resting PVRi is flow dependent in pulmonary arterial hypertension patients. Thus, a decrease in PVRi indicates pulmonary vasodilatation only if the driving pressure and $\mathrm{CO}$ are changing in the opposite direction [12]. When haemodynamics are assessed in resting conditions, vasodilatation can be certified if PVRi significantly decreases together with an increase or unchanged CI and a decrease in driving pressure $\left(\bar{P}_{\text {pa- }}-P_{\text {pao }}\right)$. When the pressure-flow relationship is available, vasodilatation is documented when the slope of the pressure-flow relationship is decreased and/or the pressureflow plot is shifted downward, so that the driving pressure is decreased for a given pulmonary flow. In order to characterise the effects of treatment on both the slope and the upward or downward shift of the pressure-flow plot, the changes in extrapolated isoflow $\bar{P}_{\text {pa }}$ were calculated as a single index of response to vasodilator treatment. To this end, the reference isoflow value was first defined as the lowest of the two peak exercise $\mathrm{CI}$ values recorded before and after treatment. The corresponding isoflow $\bar{P}_{\text {pa }}$ was extrapolated from the two $\bar{P}_{\text {pa- }}$ CI regression lines. Treatment-induced changes in extrapolated isoflow $\bar{P}_{\text {pa }}$ were then calculated (fig. 1).

Each of nine patients underwent two haemodynamic evaluations during exercise $30 \mathrm{~min}$ apart, in order to evaluate the variability of resting PVRi and isoflow $\bar{P}_{\text {pa. }}$. Overall, the mean $\bar{P}_{\text {pa-CI }}$ slope remained unchanged (from 23.6 \pm 12.6 to $\left.23.1 \pm 10.5 \mathrm{mmHg} \cdot \mathrm{L}^{-1} \cdot \mathrm{min} \cdot \mathrm{m}^{-2} ; \mathrm{p}=0.703\right)$. The mean PVRi also remained unchanged (from $19.0 \pm 6.8$ to $19.1 \pm 7.8 \mathrm{mmHg} \cdot \mathrm{L}^{-1}$. $\left.\mathrm{min} \cdot \mathrm{m}^{-2} ; \mathrm{p}=0.924\right)$. The $95 \%$ confidence interval of the mean relative difference between the two resting PVRi values was -20$18 \%$. Finally, isoflow $\bar{P}_{\text {pa }}$ remained unchanged (from $70.7 \pm 18.1$ to $\left.71.2 \pm 20.5 \mathrm{mmHg} \cdot \mathrm{L}^{-1} \cdot \mathrm{min} \cdot \mathrm{m}^{-2} ; \mathrm{p}=0.802\right)$. The $95 \%$ confidence interval of the mean relative difference between the two isoflow

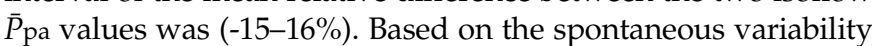
in these nine patients and variability of PVRi previously reported $[13,14]$, only changes in PVRi $>20 \%$ and changes in isoflow $\bar{P}_{\text {pa }}$ $>15 \%$ were considered meaningful. 


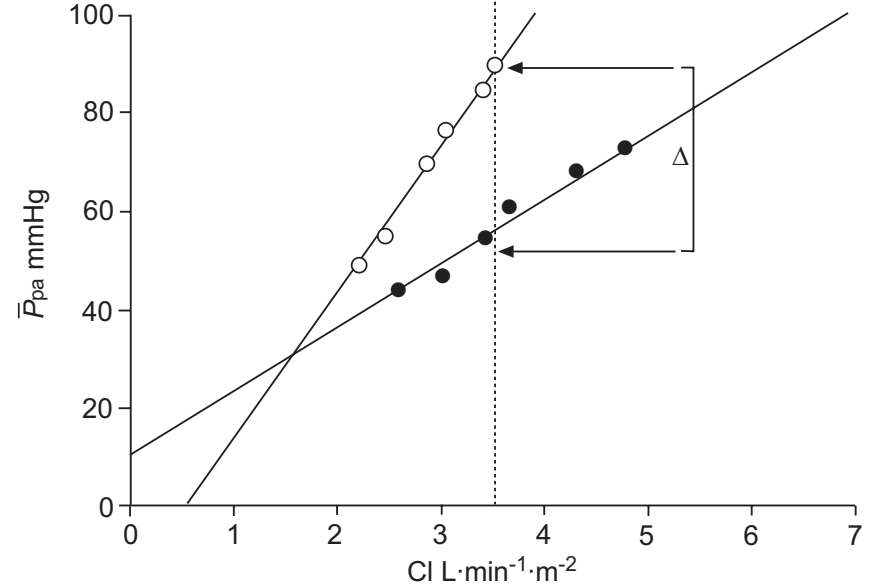

FIGURE 1. Calculation of treatment-induced changes in isoflow mean pulmonary artery pressure $(\bar{P}$ pa). The reference isoflow value $(\cdots \cdots .$.$) was first$ defined as the lowest of the two peak exercise cardiac index $(\mathrm{Cl})$ values observed before and after treatment. The corresponding isoflow $\bar{P}$ pa values before $(O)$ and after $(\bullet)$ treatment were extrapolated from the two $\bar{P}$ pa- $\mathrm{Cl}$ regression lines (arrows), and the change in isoflow $\bar{P}_{\mathrm{pa}}(\Delta)$ was calculated.

\section{Statistical analysis}

Data are expressed as mean $\pm \mathrm{SD}$. Mean values at baseline and after treatment were compared using paired t-tests. A p-value $<0.05$ was considered statistically significant. Linear regression analysis was performed using the least squares method. Univariate regression analysis was performed between treatment-induced changes in the 6MWD and changes in resting and exercise haemodynamics and changes in the chronotropic response during the 6-min walk test [11]. Multivariate regression analyses was used to examine the independent effect of each variable on changes in 6MWD, controlling for confounding variables and using variables with $p<0.20$ on univariate analysis. Similar to recent trials in IPAH, the median increase in 6MWD following therapy was $40 \mathrm{~m}$. This cut-off value was used to assess the accuracy of haemodynamic variables in predicting significant changes in 6MWD. The authors had full access to the data and take responsibility for its integrity.

\section{RESULTS}

The clinical and haemodynamic characteristics of the present study population at baseline and after treatment are reported in table 1. After $5 \pm 2$ months of therapy, the WHO functional class was improved in 14 (33\%) patients and unchanged in 28 $(67 \%)$. As compared to pre-treatment resting values, CI

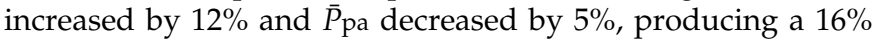
decrease in PVRi (table 1).

Individual responses were heterogeneous: using the rigorously defined criteria of vasodilatation at rest (including a decrease in resting PVRi $>20 \%$ together with an increased or unchanged $\mathrm{CI}$ and a decrease in $\bar{P}_{\text {pa- }}$ pao), a significant vasodilator effect of treatment was certified in $13(31 \%)$ of the patients.

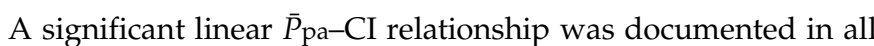
patients both before and after treatment $\left(R^{2}\right.$ 0.67-0.99; each $\mathrm{p}<0.05)$. The mean values for $\bar{P}_{\mathrm{pa}}-\mathrm{CI}$ slope and intercept at baseline were $21.3 \pm 10.9 \mathrm{mmHg} \cdot \mathrm{L}^{-1} \cdot \mathrm{min} \cdot \mathrm{m}^{-2}$ and $4 \pm 27 \mathrm{mmHg}$,

\begin{tabular}{|c|c|c|c|c|}
\hline \multirow[t]{2}{*}{ TABLE 1} & \multicolumn{4}{|c|}{$\begin{array}{l}\text { Clinical and haemodynamic characteristics of } \\
\text { patients }^{\#}\end{array}$} \\
\hline & & $\begin{array}{l}\text { Before } \\
\text { treatment }\end{array}$ & $\begin{array}{c}\text { After } \\
\text { treatment }\end{array}$ & p-value \\
\hline \multicolumn{5}{|c|}{ WHO functional class } \\
\hline ॥ & & 10 & 22 & \\
\hline III & & 30 & 20 & \\
\hline IV & & 2 & 0 & \\
\hline 6MWD m & & $399 \pm 88$ & $442 \pm 86$ & $<0.001$ \\
\hline \multicolumn{5}{|c|}{ Resting haemodynamics } \\
\hline $\bar{P}_{\text {sa }} \mathrm{mmHg}$ & & $88 \pm 12$ & $88 \pm 15$ & 0.804 \\
\hline$f_{C}$ beats $\cdot \mathrm{mir}$ & & $81 \pm 11$ & $83 \pm 11$ & 0.156 \\
\hline Pिra mmHg & & $8 \pm 5$ & $8 \pm 4$ & 0.625 \\
\hline $\bar{P}$ pa $\mathrm{mmHg}$ & & $55 \pm 13$ & $52 \pm 14$ & 0.038 \\
\hline Ppao $\mathrm{mmHg}$ & & $8 \pm 3$ & $9 \pm 3$ & 0.051 \\
\hline $\mathrm{Cl} \mathrm{L} \cdot \mathrm{min}^{-1} \cdot \mathrm{n}$ & & $2.56 \pm 0.69$ & $2.85 \pm 0.65$ & $<0.001$ \\
\hline $\mathrm{SVi} \mathrm{mL} \cdot \mathrm{m}^{-2}$ & & $32 \pm 10$ & $35 \pm 10$ & 0.015 \\
\hline PVRi $\mathrm{mmHg}$ & $L^{-1} \cdot \min \cdot m^{-2}$ & $19.4 \pm 6.6$ & $16.3 \pm 6.4$ & $<0.001$ \\
\hline $\mathrm{Sv}_{\mathrm{N}} \mathrm{O}_{2} \%$ & & $63 \pm 8$ & $64 \pm 8$ & 0.114 \\
\hline \multicolumn{5}{|c|}{ Exercise haemodynamics } \\
\hline$\overline{\mathrm{P}} \mathrm{pa}-\mathrm{Cl}$ slop & $\mathrm{mmHg} \cdot \mathrm{L}^{-1} \cdot \mathrm{min} \cdot \mathrm{m}^{-2}$ & $21.3 \pm 10.9$ & $21.5 \pm 15.2$ & 0.953 \\
\hline Peak $\bar{P}$ pa m & $\mathrm{Hg}$ & $76 \pm 16$ & $76 \pm 17$ & 0.817 \\
\hline Peak Cl L.m & $n^{-1} \cdot m^{-2}$ & $3.71 \pm 1.24$ & $4.29 \pm 1.26$ & $<0.001$ \\
\hline Isoflow $\bar{P}$ pa & $\mathrm{mHg}$ & $73 \pm 15$ & $66 \pm 18$ & 0.006 \\
\hline Peak RVSW & $\mathrm{g} \cdot \mathrm{m} \cdot \mathrm{m}^{-2} \cdot$ beat $^{-1}$ & $27 \pm 13$ & $30 \pm 11$ & 0.034 \\
\hline
\end{tabular}

Data are presented as $n$ or mean $\pm \mathrm{SD}$, unless otherwise specified. WHO: World Health Organization; 6MWD: 6-min walking distance; $\bar{P}_{\text {sa: }}$ mean systemic arterial pressure; $f \mathrm{C}$ : cardiac frequency; $\bar{P}_{\mathrm{ra}}$ : mean right atrial pressure; $\overline{\mathrm{P}} \mathrm{pa}$ mean pulmonary arterial pressure; $P$ pao: pulmonary arterial occlusion pressure $\mathrm{Cl}$ : cardiac index; SVi: stroke volume index; PVRi: pulmonary vascular resistance index; $\mathrm{Sv}_{1} \mathrm{O}_{2}$ : mixed venous oxygen saturation; RVSWI: right ventricular stroke work index. ${ }^{\#}: \mathrm{n}=42$; ": the workload at peak exercise was $20 \mathrm{~W}(\mathrm{n}=13), 30 \mathrm{~W}(\mathrm{n}=13)$ or $40 \mathrm{~W}(\mathrm{n}=16)$ before treatment and $20 \mathrm{~W}(\mathrm{n}=6)$ $30 \mathrm{~W}(n=15)$ or $40 \mathrm{~W}(\mathrm{n}=21)$ after treatment.

respectively. Peak $\bar{P}_{\text {pa }}$ was unchanged after treatment, whereas peak $C I$ increased, resulting in a decrease in mean isoflow $\bar{P}_{\text {pa }}$ (table 1). A significant decrease in isoflow $\bar{P}_{\text {pa, indicating }}$ vasodilatation at exercise, was observed in 19 (45\%) patients, whereas isoflow $\bar{P}_{\text {pa }}$ remained unchanged or increased in 19 $(45 \%)$ and $4(10 \%)$ patients, respectively.

Various combinations of changes in slopes and/or upward or downward shift (i.e. changes in resting PVRi) of the $\bar{P}_{\text {pa }}-\mathrm{CI}$ lines were observed (fig. 2). This resulted in the following paradoxical situations: among patients with significant vasodilatation at exercise $\left(>15 \%\right.$ decrease in isoflow $\left.\bar{P}_{\text {pa }}\right)$, only 10 $(53 \%)$ out of 19 met criteria for vasodilatation at rest and, conversely, among patients with significant vasodilatation at rest three $(23 \%)$ out of 13 displayed no significant vasodilatation at exercise (unchanged or increased isoflow $\bar{P}_{\mathrm{pa}}$ ).

\section{Correlates of treatment-induced changes in the 6MWD}

Changes in the 6MWD significantly correlated with changes in numerous haemodynamic variables, as well as to changes in chronotropic response (table 2). In multivariate analysis, only changes in isoflow $\bar{P}_{\text {pa }}$ (regression coefficient \pm SE $-2.551 \pm 0.373$; 

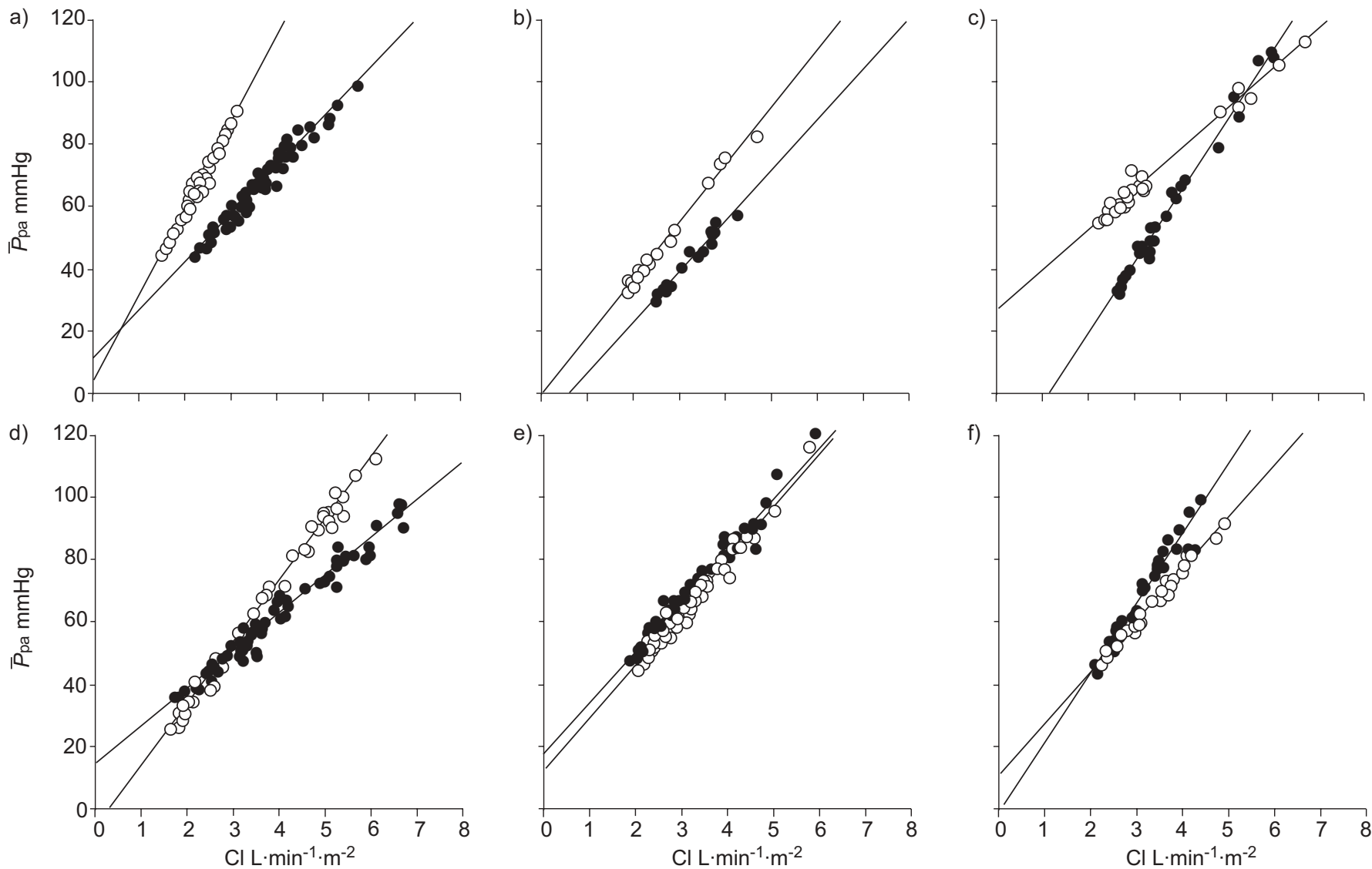

FIGURE 2. Relationship between mean pulmonary artery pressure $(\bar{P}$ pa) and cardiac index $(\mathrm{Cl})$ before $(\bigcirc)$ and after $(\bullet)$ treatment, according to the pattern of treatmentinduced changes in pressure-flow relationship as follows. Slope of the $\bar{P}$ pa-Cl relationship decreased (a and d), was unchanged (b and e) or increased (c and f); and resting pulmonary vascular resistance index (PVRi) decreased ( $a, b$ and $c$ ) or was unchanged ( $d$, e and f). Based on the spontaneous variability in the nine patients evaluated 30 min apart and previously used threshold values of PVRi changes, only $\bar{P}$ pa-Cl slope changes $>20 \%$ and resting PVRi changes $>20 \%$ were considered meaningful. For graph representation, $\bar{P}$ pa and $\mathrm{Cl}$ at rest and at each workload were plotted after the $\bar{P}$ pa values were transformed using the method developed by Poon [15]. The number of subjects and regression lines represented on each graph are as follows. a) $n=9 ; y=28 x+3$ and $R^{2}=0.97$ before treatment; $y=15.4 x+11.2$ and $R^{2}=0.96$ after treatment. b) $n=3 ; y=18 x-1$ and $R^{2}=0.99$ before treatment; $y=16 x-10$ and $R^{2}=0.97$ after treatment. c) $n=5 ; y=13 x+27$ and $R^{2}=0.98$ before treatment; $y=23 x-26$ and $R^{2}=0.99$ after treatment. d) $n=9$; $y=20 x-7$ and $R^{2}=0.99$ before treatment; $y=12 x+14$ and $R^{2}=0.97$ after treatment. e) $n=11 ; y=17 x+14$ and $R^{2}=0.98$ before treatment; $y=16 x+18$ and $R^{2}=0.98$ after treatment. f) $n=5 ; y=17 x+11$ and $R^{2}=0.98$ before treatment; $y=22 x-2$ and $R^{2}=0.94$ after treatment.

$\mathrm{p}<0.001$; fig. 3) and changes in chronotropic response during the 6-min walking test (regression coefficient 1.368 $\pm 0.447 ; \mathrm{p}=0.004$; fig. 4) were independently associated with changes in the 6MWD. When isopressure CI was similarly extrapolated from the two $\bar{P}$ pa-CI regression lines, changes in exercise capacity also correlated with changes in isopressure $\mathrm{CI}\left(\mathrm{R}^{2}=0.42\right)$.

The sensitivity, specificity, and positive and negative predictive values for a $>15 \%$ decrease in isoflow $\bar{P}_{\text {pa }}$ to detect patients with improvement in 6MWD $>40 \mathrm{~m}$ (median) were 76, 86, 84 and $78 \%$, respectively. Conversely, these values were 43, 81, 69 and $59 \%$, respectively, for significant vasodilatation at rest.

\section{DISCUSSION}

The main finding of the present study was that improvements in 6MWD were only related to changes in exercise pulmonary haemodynamics in multivariate analysis. In treated IPAH patients with improved 6MWD, peak CI was achieved at a lower $\bar{P}_{\text {pa }}$ after treatment. These results indicate that changes in exercise haemodynamics were more accurate for the prediction of improvement in exercise capacity in IPAH patients after chronic treatment than changes in resting haemodynamics were. Changes in the $6 \mathrm{MWD}$, which provides benchmark values for disease severity, response to therapy and progression, may therefore be viewed as a noninvasive marker of exercise haemodynamic response to therapy in IPAH.

Recent guidelines have suggested that pulmonary pressureflow analysis may significantly improve the evaluation of treatment responses in patients with IPAH and that studies are needed in order to document the value of haemodynamic studies during exercise in IPAH [16]. After chronic treatment, $31 \%$ of IPAH patients had pulmonary vasodilation using criteria determined from resting haemodynamics; the proportion rises to $45 \%$ when criteria derived from exercise studies are used. Such a discrepancy was expected, as vasodilation is more precisely defined by studying treatment-induced changes in exercise haemodynamics than resting haemodynamics. In addition, the present study indicated that the 


\begin{tabular}{|c|c|c|c|c|}
\hline \multirow[t]{2}{*}{ TABLE 2} & \multicolumn{4}{|c|}{$\begin{array}{l}\text { Correlation between changes in } 6 \text {-minute } \\
\text { walking distance and changes in haemodynamic } \\
\text { parameters and chronotropic response } \\
\text { observed after treatment }\end{array}$} \\
\hline & & Estimate & $\mathbf{R}^{2}$ & p-value \\
\hline \multicolumn{5}{|c|}{ Resting haemodynamics } \\
\hline $\bar{P}_{\text {ra }} \mathrm{mmHg}$ & & 0.93 & 0.00 & 0.701 \\
\hline $\bar{P}$ pa $\mathrm{mmHg}$ & & -1.17 & 0.02 & 0.348 \\
\hline $\mathrm{CI} \mathrm{L} \cdot \mathrm{min}^{-1} \cdot \mathrm{r}$ & & 64.5 & 0.26 & $<0.001$ \\
\hline $\mathrm{SVi} \mathrm{mL} \cdot \mathrm{m}^{-1}$ & & 3.7 & 0.16 & 0.006 \\
\hline PVRi mmHc & $\cdot L^{-1} \cdot \min \cdot m^{-2}$ & -6.2 & 0.26 & $<0.001$ \\
\hline $\mathrm{Sv}, \mathrm{O}_{2} \%$ & & 4.7 & 0.16 & 0.017 \\
\hline \multicolumn{5}{|c|}{ Exercise haemodynamics } \\
\hline \multicolumn{2}{|c|}{$\bar{P}$ pa-Cl slope $\mathrm{mmHg} \cdot \mathrm{L}^{-1} \cdot \mathrm{min} \cdot \mathrm{m}^{-2}$} & -2.1 & 0.24 & $<0.001$ \\
\hline \multicolumn{2}{|c|}{ Peak $\bar{P}$ pa mmHg } & -0.99 & 0.02 & 0.373 \\
\hline \multicolumn{2}{|c|}{ Peak CI L. $\min ^{-1} \cdot \mathrm{m}^{-2}$} & 40.7 & 0.34 & $<0.001$ \\
\hline \multicolumn{2}{|c|}{ Isoflow $\overline{P p a} \mathrm{mmHg}$} & -2.8 & 0.54 & $<0.001$ \\
\hline \multicolumn{2}{|c|}{ Peak RVSWi $\mathrm{g} \cdot \mathrm{m} \cdot \mathrm{m}^{-2} \cdot$ beat $^{-1}$} & 3.1 & 0.18 & 0.003 \\
\hline \multicolumn{2}{|c|}{$\begin{array}{l}\text { Chronotropic response during the } 6 \mathrm{MWT} \\
\text { beats } \mathrm{min}^{-1}\end{array}$} & 1.9 & 0.18 & 0.005 \\
\hline
\end{tabular}

Changes in haemodynamic and exercise parameters correspond to absolute changes. Similar correlation coefficients were obtained when relative changes were considered. $\bar{P}_{\text {ra: }}$ mean right atrial pressure; $\bar{P}$ pa: mean pulmonary arterial pressure; Cl: cardiac index; SVi: stroke volume index; PVRi: pulmonary vascular resistance index; $\mathrm{Sv}_{1} \mathrm{O}_{2}$ : mixed venous oxygen saturation; RVSWi: right ventricular stroke work index; 6MWT: 6-min walking test. \#: $n=42$; $\because$ : chronotropic response is the difference between peak heart rate during $6 \mathrm{MWT}$ and the resting heart rate measured before the $6 \mathrm{MWT}$

use of isoflow $\bar{P}_{\text {pa }}$ (figs 1, 2 and 3 ) may improve the clinical applicability of haemodynamic studies during exercise, especially for future clinical trials $[6,7]$, given that this simple index takes into account the overall combined influences of both resting PVRi and slope of the $\bar{P}_{\text {pa-flow relationship on }}$ exercise. Conversely, $\bar{P}$ pa-CI slope does not take into account

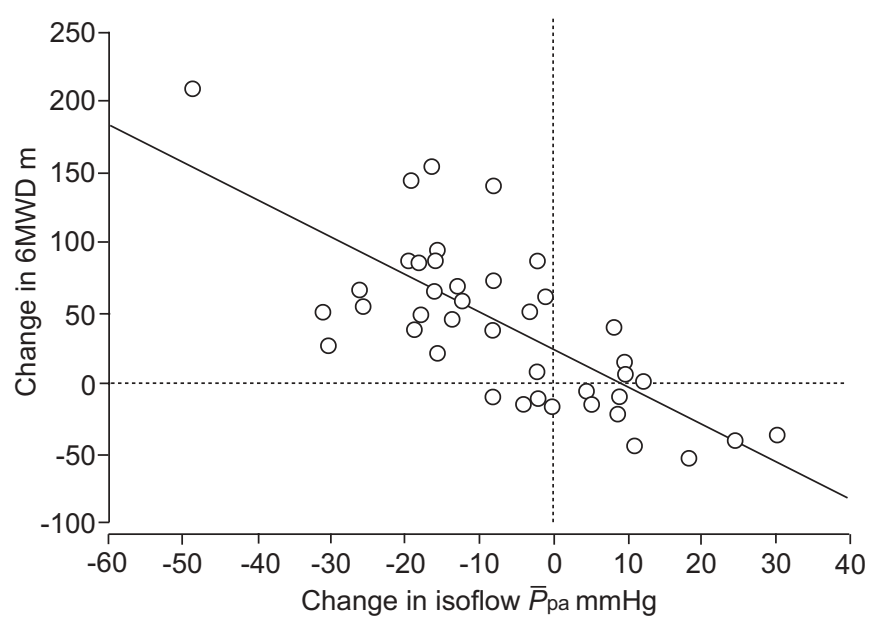

FIGURE 3. Correlation between changes in isoflow mean pulmonary artery pressure $\left(\bar{P}_{\mathrm{pa}}\right)$ and changes in 6 -min walking distance $(6 \mathrm{MWD})$ following chronic therapy. $y=-2.7 x+23$ and $R^{2}=0.54 ; p<0.001$

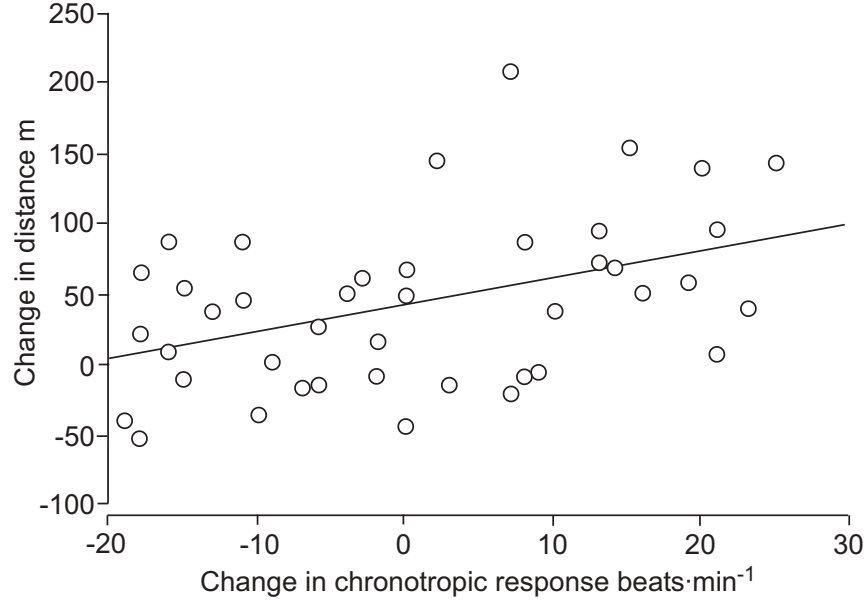

FIGURE 4. Relationship between treatment-induced changes in the 6-min walking distance and treatment-induced changes in the chronotropic response $R^{2}=0.18 ; p=0.005$

the potential shift of the pressure-flow plot. This is emphasised by the fact that, despite significant vasodilatation during exercise, mean $\bar{P}_{\text {pa }}-\mathrm{CI}$ slopes were unchanged after therapy. Furthermore, individual relative changes in $\bar{P}_{\text {pa }}-\mathrm{CI}$ slope were not independently related to changes in clinical status. Importantly, isoflow $\bar{P}_{\text {pa }}$ was used as an index to characterise the effects of treatment on the pressure-flow plot, rather than as a surrogate marker of maximal CO. This may explain why isoflow $\bar{P}$ pa was more closely correlated to functional capacity than isopressure flow in the present study.

As previously documented in a different cohort from the current authors' laboratory [11], the present study also indicated that chronotropic response during the walk test is independently associated with the 6MWD in IPAH. A chronotropic incompetence has been initially described in congestive heart failure [17]. This is believed to be due to downregulation of $\beta$-adrenoreceptors. More recently, downregulation of right ventricular myocardial $\beta$-adrenoreceptors [18] and a decreased chronotropic response during exercise has also been described in pulmonary arterial hypertension [19, 20]. These results suggest that the lack of chronotropic response may reflect the loss of normal physiological reserve in more unwell patients [11]. Interestingly, heart rate response to exercise has been shown to correlate independently with exercise capacity in a large cohort of patients with congenital heart disease [21].

The limitations of the present study should be discussed. In addition to right heart function and pulmonary circulation, other factors (including ventilation/perfusion mismatch, hypoxaemia, peripheral oxygen transportation/utilisation and impaired skeletal muscle function) may have significantly influenced the functional status of the patients [22]. Thus, the potential link between changes in functional status and haemodynamic responses to therapy needs to be interpreted with caution and remains to be confirmed in a larger sample. The role of exercise-induced pulmonary vasoconstriction may also be involved in the haemodynamic characteristics of the

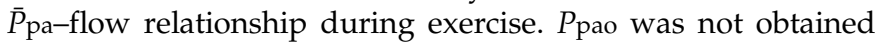
during exercise for all patients. However, in the 19 patients in 
whom $P$ pao was assessed throughout exercise, $P$ pao remained unchanged following therapy. Thus changes in the $\bar{P}_{\mathrm{pa}}-\mathrm{CI}$ relationship are likely to accurately reflect changes in the $\left(\bar{P}_{\text {pa- }}\right.$ $P$ pao)/CI relationship. As only patients with IPAH were studied, further studies are needed in the more heterogeneous population of patients with nonidiopathic pulmonary arterial hypertension, in whom nonhaemodynamic components cause major functional limitations (e.g. ascites in portopulmonary hypertension). Differences in patient characteristics at baseline precluded comparisons of treatment effects specific of bosentan versus epoprostenol. Indeed, baseline characteristics of IPAH patients determine therapeutic choices, with patients having more severe disease being more likely to receive epoprostenol therapy. Finally, recordings of exercise haemodynamics in $\mathrm{IPAH}$ requires an intensive protocol, at best performed by an experienced team, and thus do not belong to the routine evaluation of IPAH patients. Thus, the current authors wish to emphasise the fact that the present study did not aim to recommend exercise haemodynamics as a treatment end-point, but rather to precisely determine the haemodynamic correlates of clinical improvements in treated IPAH patients.

Recent guidelines have suggested that pulmonary pressureflow analysis may improve the evaluation of treatment responses in patients with idiopathic pulmonary arterial hypertension. In chronically treated idiopathic pulmonary arterial hypertension with improved functional capacity, peak cardiac index was achieved at a lower mean pulmonary artery pressure after treatment. From a practical point of view, these results reinforce the value of the noninvasive 6-min walk test as a marker of exercise haemodynamic response.

\section{REFERENCES}

1 Humbert M, Sitbon O, Simonneau G. Treatment of pulmonary arterial hypertension. N Engl J Med 2004; 351: 1425-1436.

2 Galie N, Torbicki A, Barst R, et al. Guidelines on diagnosis and treatment of pulmonary arterial hypertension. The Task Force on Diagnosis and Treatment of Pulmonary Arterial Hypertension of the European Society of Cardiology. Eur Heart J 2004; 25: 2243-2278.

3 McGregor M, Sniderman A. On pulmonary vascular resistance: the need for more precise definition. Am J Cardiol 1985; 55: 217-221.

4 Naeije R, Vizza D. Current perspectives modern hemodynamic evaluation of the pulmonary circulation. Application to pulmonary arterial hypertension and embolic pulmonary hypertension. Ital Heart J 2005; 6: 784-788.

5 Chemla D, Castelain V, Herve P, Lecarpentier Y, Brimioulle S. Haemodynamic evaluation of pulmonary hypertension. Eur Respir J 2002; 20: 1314-1331.

6 Hoeper MM, Oudiz RJ, Peacock A, et al. End points and clinical trial designs in pulmonary arterial hypertension: clinical and regulatory perspectives. J Am Coll Cardiol 2004; 43: Suppl. 12, 48S-55S.
7 Peacock A, Naeije R, Galie N, Reeves JT. End points in pulmonary arterial hypertension: the way forward. Eur Respir J 2004; 23: 947-953.

8 Simonneau G, Galie N, Rubin LJ, et al. Clinical classification of pulmonary hypertension. J Am Coll Cardiol 2004; 43: Suppl. 12, 5S-12S.

9 Barst RJ, McGoon M, Torbicki A, et al. Diagnosis and differential assessment of pulmonary arterial hypertension. J Am Coll Cardiol 2004; 43: Suppl. 12, 40S-47S.

10 ATS Committee on Proficiency Standards for Clinical Pulmonary Function Laboratories. ATS statement: guidelines for the six-minute walk test. Am J Respir Crit Care Med 2002; 166: 111-117.

11 Provencher S, Chemla D, Herve P, Sitbon O, Humbert M, Simonneau G. Heart rate responses during the 6-minute walk test in pulmonary arterial hypertension. Eur Respir J 2006; 27: 114-120.

12 Naeije R. Pulmonary vascular resistance. A meaningless variable? Intensive Care Med 2003; 29: 526-529.

13 Rich S, D'Alonzo GE, Dantzker DR, Levy PS. Magnitude and implications of spontaneous hemodynamic variability in primary pulmonary hypertension. Am J Cardiol 1985; 55: 159-163.

14 Rich S, Kaufmann E, Levy PS. The effect of high doses of calcium-channel blockers on survival in primary pulmonary hypertension. N Engl J Med 1992; 327: 76-81.

15 Poon CS. Analysis of linear and mildly nonlinear relationships using pooled subject data. J Appl Physiol 1988; 64: 854-859.

16 McGoon M, Gutterman D, Steen V, et al. Screening, early detection, and diagnosis of pulmonary arterial hypertension: ACCP evidence-based clinical practice guidelines. Chest 2004; 126: Suppl. 1, 14S-34S.

17 Colucci WS, Ribeiro JP, Rocco MB, et al. Impaired chronotropic response to exercise in patients with congestive heart failure. Role of postsynaptic $\beta$-adrenergic desensitization. Circulation 1989; 80: 314-323.

18 Bristow MR, Minobe W, Rasmussen R, et al. $\beta$-Adrenergic neuroeffector abnormalities in the failing human heart are produced by local rather than systemic mechanisms. J Clin Invest 1992; 89: 803-815.

19 Riley MS, Porszasz J, Engelen MP, Brundage $\mathrm{BH}$, Wasserman K. Gas exchange responses to continuous incremental cycle ergometry exercise in primary pulmonary hypertension in humans. Eur J Appl Physiol 2000; 83: 63-70.

20 Deboeck G, Niset G, Lamotte M, Vachiery JL, Naeije R. Exercise testing in pulmonary arterial hypertension and in chronic heart failure. Eur Respir J 2004; 23: 747-751.

21 Diller GP, Dimopoulos K, Okonko D, et al. Exercise intolerance in adult congenital heart disease: comparative severity, correlates, and prognostic implication. Circulation 2005; 112: 828-835.

22 Sun XG, Hansen JE, Oudiz RJ, Wasserman K. Exercise pathophysiology in patients with primary pulmonary hypertension. Circulation 2001; 104: 429-435. 